KROHN, N.G.; MISSIO, R.F.; ORTOLAN, M.L.; BURIN, A.; STEINMACHER, D.A. LOPES, M.C. Teores de nitrato em folhas de alface em função do horário de coleta e do tipo de folha amostrada. Horticultura Brasileira, Brasília, v. 21, n. 2, p. 216-219, abril/junho 2003.

\title{
Teores de nitrato em folhas de alface em função do horário de coleta e do tipo de folha amostrada
}

\author{
Nádia G. Krohn²; Robson F. Missio²; Mara L. Ortolan²; Alcione Burin²; Douglas A. Steinmacher²; Mário \\ César Lopes ${ }^{1}$ \\ ${ }^{1}$ UNIOESTE, Rua Pernambuco, no 1777, 85960-000, Marechal Cândido Rondon-PR; E.mail: mclopes@unioeste.br; ${ }^{2}$ Estudante de \\ Agronomia da UNIOESTE
}

\section{RESUMO}

Determinou-se os teores de nitrato em função dos horários de coleta e avaliou-se o critério de amostragem de folhas, para alface do tipo americana. As plantas foram colhidas na UNIOESTE, Campus de Marechal Cândido Rondon, em diferentes horários, às 0; 6; 12 e 18 horas. Após colhidas as folhas foram lavadas em água corrente e destilada, descartando-se as nervuras centrais, sendo separadas da seguinte forma: folhas maturas (externas), folhas recémmaturas (medianas) e folhas jovens (internas). Determinou-se então a massa seca e os teores de nitrato. Observaram-se diferenças significativas nos horários de coleta, sendo que durante o dia foram encontrados os menores valores de teores de nitrato e durante a noite os maiores. Em relação ao critério de amostragem tem-se que as folhas jovens apresentaram maior teor de nitrato, $999 \mathrm{mg}$ de $\mathrm{N}_{-} \mathrm{NO}_{3}$ . $\mathrm{kg}^{-1}$ de massa seca, enquanto que as folhas maturas e recém-maturas apresentaram 564 e $468 \mathrm{mg}$ de N-NO${ }_{3}^{-} \cdot \mathrm{kg}^{-1}$ de massa seca, respectivamente.

Palavras-chave: Lactuca sativa L., intensidade luminosa, análise foliar, nutrição.

\begin{abstract}
Nitrate level on lettuce leaves in function of the harvest time and leaf type sampling

The nitrate levels in function of the harvest times, and the sampling criterion of american type lettuce leaves were determined. The plants were harvested at UNIOESTE in Marechal Cândido Rondon, Paraná State, Brazil, at 0 o'clock, 6 a.m., 12 o'clock and 6 p.m. In sequence, the leaves were washed, discarding the central nervure, later they were separated according to mature leaves (external leaves), recently mature leaves (median leaves) and new leaves (internal leaves). The dry weight and the nitrate level were determined. Leaves harvested during the day presented lower values of nitrate levels in comparison to leaves harvested during the night. About the sampling criterion the nitrate levels were superior in new leaves, $999 \mathrm{mg}$ of $\mathrm{N}-\mathrm{NO}_{3} \cdot \mathrm{kg}^{-1}$ dry weight, while the mature leaves and the recently matured leaves accumulated 564 and $468 \mathrm{mg}$ of $\mathrm{N}$ $\mathrm{NO}_{3}^{-} \cdot \mathrm{kg}^{-1}$ dry weight, respectively.
\end{abstract}

Keywords: Lactuca sativa L., light intensity, leaf analysis, nutrition.

(Recebido para publicação em 12 de julho de 2002 e aceito em 09 de abril de 2003)

A alface (Lactuca sativa, L.) é considerada a hortaliça folhosa mais importante na alimentação do brasileiro, o que lhe assegura expressiva importância econômica. De acordo com Somogyi (1988) e Preussmann (1988) citados por Pomerening et al. (1992) as hortaliças contribuem com cerca de $70 \%$ da ingestão diária de nitrato. Andriolo (1999) afirma que na planta o nitrogênio é dirigido preferencialmente para as partes fotossinteticamente mais ativas. Assim sendo, as hortaliças folhosas, são aquelas que apresentam maior risco de acumular teores de nitrato nocivos ao consumidor.

Os nitratos e nitritos ingeridos pelo homem contribuem para a formação endógena de $\mathrm{N}$-nitrosaminas, compostos potencialmente cancerígenos, que são capazes de transformar a hemoglobina do sangue em ferriemoglobina, processo que leva ao impedimento do transporte do oxigênio dos alvéolos pulmonares para os tecidos (Rath et al., 1994). A capacidade de acúmulo de nitrato pelas plantas é de caráter genético. No que tange a alface, diversos trabalhos demonstram que diferentes cultivares apresentam variados teores de nitrato. Bonnecarrère et al. (2000a) encontraram valores (mg de $\mathrm{N}$ $\mathrm{NO}_{3}^{-} \cdot \mathrm{kg}^{-1}$ de massa seca) variando de 465 a 646 para as cultivares de alface lisa, de 600 a 889 para as crespas e de 538 para as do tipo americana. Já Bonnecarrère et al. (2000b) constataram valores (mg de $\mathrm{N}^{-\mathrm{NO}_{3}} \cdot \mathrm{kg}^{-1}$ de massa seca) de 272 a 308 para cultivares de alface lisa e de 243 a 346 para as crespas. Cavarianni et al. (2000a) também avaliando cultivares, encontraram valores ( $\mathrm{mg}$ de $\mathrm{N}-\mathrm{NO}_{3}^{-} \cdot \mathrm{kg}^{-1}$ de massa seca) de 1545 a 1963 para alface lisa, de 1242 a 1536 para as crespas e de 1030 a 1965 para a do tipo americana. No entanto Cavarianni et al. (2000b) verificaram valores de 546 a 1466 para cultivares de alface lisa, de 1475 a 1661 para as crespas e de 694 a 1942 para as do tipo americana. Por fim, Pilau et al. (2000) observaram valores 101 a 250 para cultivares de alface lisa e de 91 a 237 para as crespas.

Além das cultivares, os teores de nitrato são influenciados por outros fatores como intensidade luminosa (Grazia et al., 2001), sistema de cultivo (Cavarianni et al., 2000a, b; Rezende et al., 2000) e adubação ou composição da solução nutritiva (Castro \& Ferraz, 1998; Bonnecarrère et al., 2000b; Fontes et al., 1995; Sanches et al., 2001).

O horário de coleta da amostra também afeta os teores de nitrato. Andriolo (1999) explica que o acúmulo deste íon nos tecidos vegetais ocorre quando existe desequilíbrio entre a absorção e a assimilação do mesmo. A assimilação de nitrato supre a síntese dos compostos nitrogenados na planta, principalmente as enzimas. De acordo com Ferri (1985), 
durante o dia e sob maiores intensidades luminosas, a planta apresenta maior atividade fotossintética, elevando a produção de NADH (cofator da redutase do nitrato) conseqüentemente, maior quantidade de nitrato é assimilada, enquanto que durante a noite ocorre o acúmulo nos vacúolos. Deste modo, Carrasco \& Burrage (1992) e Cardenás-Navarro et al. (1999) estudando o horário de amostragem em alface, observaram teores decrescentes durante o dia e crescentes durante a noite. No entanto, verifica-se a necessidade de elucidar a flutuação diária dos níveis de nitrato.

Diversos trabalhos relacionados à amostragem para análise foliar estabelecem metodologia para avaliação de vários nutrientes. Conforme Trani et al. (1983) o procedimento de amostragem para análise foliar consiste na coleta da nervura mediana, da folha envolvente no aparecimento da cabeça. Sendo que Trani $\&$ Raij (1997) relatam que as folhas recém desenvolvidas, da metade a $2 / 3$ do ciclo, são as mais adequadas para utilização na determinação dos nutrientes. A metodologia estabelecida por Jones (1985) indica a utilização das folhas maturas mais jovens, na metade do ciclo, e Sanchez et al.(1991) indicam que as folhas mais externas, do início até a metade do ciclo, são as que devem ser coletadas. Já Malavolta et al. (1997) recomendam a coleta de folhas recém-maturas por ocasião da formação da cabeça.

Huett et al. (1997) estabeleceram diferentes metodologias de coleta para determinação dos diversos nutrientes; Para a determinação do nitrogênio total em alface os autores recomendam a coleta da folha envolvente, por ocasião da formação da cabeça, ou da folha matura mais jovem, do coração, no final do ciclo. Para determinação do nitrato indicam a utilização da nervura central da folha envolvente ou da parte superior das folhas no coração, quando a cabeça está formada. Mas quando a coleta for efetuada no final do ciclo recomendam a utilização de todo o ápice meristemático ou da nervura central da folha envolvente. Desta forma notam-se algumas divergências entre os trabalhos, validando a necessidade de estudos.

Behr \& Wiebe (1992) e BlomZandstra \& Lampe (1985) afirmam que com a maior incidência de radiação so-

Tabela 1. Teores de nitrato ( $\mathrm{mg} \mathrm{N}-\mathrm{NO}_{3} \cdot \mathrm{kg}^{-1}$ de massa seca) em folhas de alface do tipo americana, da cultivar Lucy Brown, coletadas em diferentes horários. Marechal Cândido Rondon (PR), UNIOESTE, 2002.

\begin{tabular}{lc}
\hline Horários de coleta & $\begin{array}{c}\mathbf{N}-\mathbf{N O}_{3}^{-} \\
\left(\mathbf{m g} \cdot \mathbf{k g}^{-1}\right)\end{array}$ \\
\hline $0: 00$ & $2374 \mathrm{a}^{*}$ \\
$6: 00$ & $2496 \mathrm{a}$ \\
$12: 00$ & $1733 \mathrm{~b}$ \\
$18: 00$ & $1875 \mathrm{~b}$ \\
\hline $\mathrm{CV}(\%)$ & 14,67
\end{tabular}

* Médias seguidas pela mesma letra não diferem ao Teste de Tukey a 5\% de probabilidade de erro.

lar ocorre menor acúmulo de nitrato nas folhas. Desta forma quando se trata de alface do tipo americana, devido a sua morfologia, as folhas recebem diferentes quantidades de radiação, podendo incorrer em erros de avaliação pela recomendação de amostragem já estabelecida.

Realizou-se o presente trabalho com o objetivo de avaliar a influência do horário de coleta, sobre o teor de nitrato em folhas de alface, como também avaliar o critério de amostragem das folhas para análise do teor de nitrato.

\section{MATERIAL E MÉTODOS}

O experimento foi conduzido na UNIOESTE, Campus de Marechal Cândido Rondon (PR). Utilizou-se alface do tipo americana, da cultivar Lucy Brown, com 60 dias de ciclo, produzida em sistema convencional na Estação Experimental Dr. Antônio Carlos dos Santos Pessoa. O solo da área é do tipo Latossolo Vermelho Eutroférrico (EMBRAPA, 1999), que por ocasião do plantio apresentava 29,98 g.dm ${ }^{3}$ de matéria orgânica. A cultura foi adubada com 150 g.m ${ }^{-2}$ da formulação 04-14-08 por ocasião do plantio, sendo que não foi efetuada adubação de cobertura, devido ao alto teor de matéria orgânica do solo. As irrigações foram realizadas quando necessárias, no período da manhã.

As amostras foram coletas em 14/ 03/02, nos seguintes horários: 0, 6, 12 e 18 horas. Em cada horário foram coletadas quatro plantas, sendo cada uma delas correspondente a uma repetição, em delineamento estatístico inteiramente casualizado.
As plantas foram levadas ao laboratório, enxaguadas em água corrente seguida de água destilada, de acordo com o procedimento recomendado por Miyazawa et al. (1999). As nervuras centrais foram retiradas e descartadas. As folhas foram separadas da seguinte forma: folhas maturas (externas), folhas recém-maturas (medianas) e folhas jovens (internas). Estas foram acondicionadas, individualmente, em recipientes de alumínio e foram secadas em estufa de circulação de ar forçada, a $65^{\circ} \mathrm{C}$ por 72 horas, para determinação de massa seca. Em seguida este material foi moído em moinho tipo Willey, peneira de 40 mesh, retirando-se amostras de $1 \mathrm{~g}$ para a determinação do $\mathrm{N}-\mathrm{NO}_{3}$ - de acordo com a metodologia proposta por Tedesco et al. (1995). O teor total do nitrato nas folhas foi obtido pela média das concentrações e massa seca total das partes analisadas (folhas maturas, recém maturas e jovens).

Os dados foram submetidos à análise de variância e as médias foram transformadas através de raiz quadrada-raiz $(\mathrm{X}+\mathrm{K})$, sendo $\mathrm{K}=0$, e comparadas pelo teste de Tukey a $5 \%$ de probabilidade de erro.

\section{RESULTADOS E DISCUSSÃO}

Não houve interação dos teores de nitrato entre os horários de coleta e folhas coletadas em diferentes posições na planta.

Quanto aos teores de nitrato nas plantas coletadas em diversos horários (Tabela 1) observam-se médias menores às 12 e 18 horas e maiores às 6 horas 
Tabela 2. Teores de nitrato ( $\mathrm{mg} \mathrm{N}-\mathrm{NO}_{3} \cdot \mathrm{kg}^{-1}$ de massa seca) em folhas de alface do tipo americana da cultivar Lucy Brown, coletadas em diferentes posições na planta. Marechal Cândido Rondon (PR), UNIOESTE, 2002.

\begin{tabular}{lc}
\hline \multicolumn{1}{c}{ Partes da planta } & $\begin{array}{c}\mathbf{N}-\mathbf{N O}_{3}^{-} \\
\left(\mathbf{m g}^{-} \mathbf{k g}^{-1}\right)\end{array}$ \\
\hline Folhas maturas & $564 \mathrm{~b}$ \\
Folhas recém maturas & $468 \mathrm{~b}$ \\
Folhas jovens & $999 \mathrm{a}$ \\
Total nas folhas & 2139 \\
\hline $\mathrm{CV}(\%)$ & 9,82 \\
\hline
\end{tabular}

* Médias seguidas pela mesma letra não diferem ao Teste de Tukey a 5\% de probabilidade de erro.

e 0 hora. Fato semelhante foi observado por Cardenás-Navarro et al. (1999) e Carrasco \& Burrage (1992). Pode-se explicar o menor teor de nitrato às 12 horas em virtude da maior intensidade luminosa. Nestas condições a planta apresenta maior atividade fotossintética, o que eleva a produção de NADH (cofator da redutase do nitrato) e maior quantidade de nitrato é reduzida a amônio (Ferri, 1985).

$\mathrm{O}$ teor total de nitrato encontrado nas folhas foi de $2139 \mathrm{mg}$ de $\mathrm{N}-\mathrm{NO}_{3}{ }^{-} \cdot \mathrm{Kg}^{-1}$ de massa seca (Tabela 2). Sendo que este valor está acima dos encontrados por Cavarianni et al. (2000a), Cavarianni et al. (2000b) e Bonnecarrère et al. (2000a) para cultivares de alface do tipo americana. No entanto, o teor está abaixo do limite estabelecido pela comunidade européia de $3000 \mathrm{mg}$ de $\mathrm{N}-\mathrm{NO}_{3} \cdot \mathrm{Kg}^{-1}$ de massa seca (McCall \& Willumsen, 1998).

Quanto aos teores encontrados nas folhas em diferentes posições na planta, observa-se que as jovens apresentam significativamente maior teor de nitrato que as demais (Tabela 2). $\mathrm{O}$ fato pode ser explicado pela morfologia de plantas de alface americana, sendo que as folhas mais jovens se encontram totalmente envolvidas pelas folhas maturas e recém-maturas, o que impede que as mesmas recebam radiação solar direta. De acordo com o discutido anteriormente, quanto menor a intensidade luminosidade recebida pelas folhas, maior o teor de nitrato encontrado, concordando com Behr \& Wiebe (1992) e Blom-Zandstra \& Lampe (1985). Assim sendo, as amostragens que atendem outros nutrientes além do nitrogênio, na análise foliar, como as propostas por
Malavolta et al. (1997), por Jones (1985) e por Trani \& Raij (1997) que recomendam a coleta de folhas recém-maturas subestimam os teores de nitrato.

Em se tratando de estudos que visam amostragens distintas para determinação dos diferentes nutrientes, como o realizado por Huett et al. (1997), verifica-se que no caso do nitrato ocorre discordância entre a metodologia estabelecida pelo autor e a do presente trabalho. Mesmo porque a metodologia não é especifica para alface do tipo americana.

Os resultados encontrados reforçam a correlação do efeito da luminosidade com os teores de nitrato apontados por Behr \& Wiebe (1992) e Blom-Zandstra \& Lampe (1985) e pela própria morfologia das cultivares do tipo americana. Assim verifica-se a necessidade de maior número de trabalhos que analisem a amostragem foliar visando determinar teores de nitrato em cultivares de alface do tipo americana. Considerando-se que a parte comercial mais utilizada é a interna, a qual apresentou os maiores valores, recomenda-se a mesma como ponto de amostragem, para a determinação dos níveis de nitrato.

\section{LITERATURA CITADA}

ANDRIOLO, J. L. Fisiologia das culturas protegidas. Santa Maria : UFSM, 1999. 142 p.

BEHR, U.; WIEBE, H.J. Relation between photosynthesis and nitrate content of lettuce cultivars. Scientia Horticulturae, v. 49, p 175-9. 1992.

BLOM-ZANDSTRA, M.; LAMPE, J.E.M. The role of nitrate in the osmoregulation of lettuce (Lactuca sativa L.) grown at different light intensities. Journal of Experimental Botany, v. 36, p. 1043-1052. 1985
BONNECARRÈRE, R.A.G.; LONDERO, F.A.A.; SANTOS, O.S.; MANFRON, P.A. Teores de nitrato em cultivares de alface em hidroponia. Horticultura Brasileira, Brasília, v. 18, suplemento, p. 288-9. 2000a.

BONNECARRÈRE, R.A.G.; SCHMIDT, D.; MANFRON, P.A; SANTOS, O.S. Teores de nitrato em plantas hidropônicas de alface em função de cultivares e soluções nutritivas. Horticultura Brasileira, Brasília, v. 18, suplemento, p. 286-7. 2000b.

CARDENÁS-NAVARRO, R.; ADAMOWICZ, S.; ROBIN, P. Nitrate accumulation in plants: a role for water. Journal of Experimental Botany, v. 50, n. 334, p. 613-624. 1999.

CARRASCO, G.A.; BURRAGE, S.W. Diurnal fluctuations in nitrate accumulation and reductase activity in lettuce (Lactuca sativa L.) grown using Nutrient Film Technique. Acta Horticulturae, v. 323, p. 51-9. 1992.

CASTRO, S.R.P.; FERRAZ JUNIOR, A.S.L. Teores de nitrato nas folhas e produção de alface cultivada com diferentes fontes de nitrogênio. Horticultura Brasileira, Brasília, v. 16, n. 1, p. 65-8. 1998.

CAVARIANNI, R.L.; CAZETTA, J.O.; MAY, A.; BARBOSA, J.C.; CECILIO FILHO, A.B. Acúmulo de nitrato em cultivares de alface, cultivadas no inverno, em função do ambiente de cultivo. Horticultura Brasileira, Brasília, v. 18, suplemento, p. 322-3. 2000a.

CAVARIANNI, R.L.; CAZETTA, J.O.; MAY, A.; BARBOSA, J.C.; CECILIO FILHO, A.B. Acúmulo de nitrato em cultivares de alface, cultivadas na primavera, em função do ambiente de cultivo. Horticultura Brasileira, Brasília, v. 18, suplemento, p. 324-5. 2000b.

EMBRAPA. Centro Nacional de Pesquisa de Solos. Sistema Brasileiro de Classificação de Solos. $4^{\text {a }}$ aproximação. Rio de Janeiro, 1999, 169 p.

FERRI, M.G. Fisiologia Vegetal. São Paulo: EPV, 1985. P. 181-209.

FONTES, P.C.R.; CONDE, R.M.; PEREIRA, R.M. Níveis críticos de $\mathrm{N}-\mathrm{NO}_{3}, \mathrm{~N}$-orgânico e de clorofila em folhas de alface e de $\mathrm{N}-\mathrm{NO}_{3}$ no solo. Horticultura Brasileira, Brasília, v. 13, n. 1, 1995. GRAZIA, J.; TITTONELL, P.A.; CHIESA, A. Acumulacion de nitratos em lechugas de hojas sueltas cultivadas bajo diferentes condiciones ambientales. Horticultura Brasileira, Brasília, v. 19, suplemento, CD ROOM, 2001.

HUETT, D.; MAIER, N.A.; SPARROW, L.A.; PIGGOTT, T.J. Plant Analysis An Interpretation Manual. In: D.J. Reuter and J.B. Robinson (eds.) Vegetable crops. Revised edition. Melbourne: CSIRO, p. 383-464, 1997.

JONES, J.B. Soil testing and plant analysis. Horticultural reviews, USA, v. 7, p. 32. USA: Edited by Jules Janick (Purdue University).1985. MALAVOLTA, E.; VITTI, G.C.; OLIVEIRA, S.A. Avaliação do estado nutricional das plantas: princípios e aplicações. 2 ed., rev. e atual. Piracicaba: POTAFOS, 1997. 319 p.

McCALL, D.; WILLUMSEN, J. Effects of nitrate, ammonium and chloride application on the yield and nitrate content of soil-grown lettuce. Journal of Horticultural Science \& Biotechnology, v. 37, n. 5, p. 698-703. 1998. 
MIYAZAWA, M.; PAVAN, M.A.; MURAOKA, T.; CARMO, C.A.F.S.; MELLO, W.J. Análises químicas de tecido vegetal. In: SILVA, F.C.(org) Manual de análises químicas de solo, plantas e fertilizantes. Brasília: EMBRAPA. 1999. P. 174. PILAU, F.G.; SCHMIDT, D.; SANTOS, O.S.; MANFRON, P.A. Teores de nitrato em cultivares de alface sob hidroponia, na primavera. Horticultura Brasileira, Brasília, v. 18, p. 276-277, 2000.

POMMERENING, B.; MASTROVITO, D.; PALAZZO, D.; VANADIA, S.; MARTELLI, S Indagine sul contenudo di nitrato negli ortaggi dell' área metropontina. Inf. Agrar., Roma, v. 19, p. $47-$ 53, 1992.

RATH, S.; XIMENES, M.I.N.; REYES, F.G.R

Teores de nitrato e nitrito em vegetais cultivados no Distrito Federal: um estudo preliminar. Revista Instituto Adolfo Lutz, v. 54, n. 2, p. 126-130, 1994.
REZENDE, A.J.; JUNQUEIRA, A.M.R; XIMENES, M.I.N.; BORGO, L.A. Teor de nitrato em alface produzida em sistema hidropônico e sistema convencional em Brasília - DF Horticultura Brasileira, Brasília, v. 18, suplemento, p. 533-4, 2000.

SANCHES, L.M.; LAURA, V.A.; FAVERO, S.; MATIAS, R. Épocas de troca de solução nutritiva por água em alface cultivada sob hidroponia e sua influência no teor de nitrato. Horticultura Brasileira, Brasília, v. 19, suplemento CD ROOM 2001.

SANCHEZ, C.A.; SNYDER, G.H.; BURDINE, H.W. Dris evaluation of the nutritional status of crisphead lettuce. Hortscience, v. 26, n. 3, p. 274276, 1991.
TEDESCO, M.J.; GIANELLO, C.; BISSANI, C.A.; BOHNEN, H.; VOLKWEISS, S.J. Análises de solo, planta e outros materiais. $2^{\mathrm{a}} \mathrm{ed}$. Revisada e ampliada. Porto Alegre: UFRGS-Faculdade de Agronomia, 1995. 174 p. (Boletim técnico, 5)

TRANI, P.E.; HIROCE, R.; BATAGLIA, O.C. Análise foliar: amostragem e interpretação. Campinas: Fundação Cargil, 1983. 18 p.

TRANI, P.; RAIJ, B.; CANTARELLA, H.; QUAGGIO, J.A.; FURLANI, A.M.C. Recomendações de adubação e calagem para o Estado de São Paulo. 2 ed. ver. atual. Campinas: Instituto Agronômico de Campinas/Fundação IAC, 1997. P. 157-162. (Boletim técnico, 100) 